\title{
An Evidence-Informed and Key Informants-Appraised Conceptual Framework for an Integrated Elderly Health Care Governance in Iran (IEHCG-IR)
}

This article was published in the following Dove Press journal: Risk Management and Healthcare Policy

\section{Mehdi Abbasian (iD) \\ Abdolreza Shaghaghi (DD}

Elderly Health Section, Health Education \& Promotion Department, Faculty of Health, Tabriz University of Medical Sciences, Tabriz, Iran
Correspondence: Abdolreza Shaghaghi Health Education \& Promotion Department, Faculty of Health, Tabriz University of Medical Sciences, Golgasht Ave, Tabriz 5I666I47II, Iran

Email shaghaghir@tbzmed.ac.ir
Purpose: Population ageing has been steadily rising in Iran and in the over 60-year-old population, the ratio increased from $5.4 \%$ in 1986 to $8.6 \%$ in 2016 which represents an increase of 4.3 million over the past three decades. The inevitable impacts of a growing elderly population on the demand-side of the health care provision (HCP) equilibrium call for an urgent revision of the current arrangements of the Iran's National health care system (INHS). The main aim of this study was to scrutinize the best available scientific evidence on the international integrated elderly health care governance (HCG) models to revamp health care practice and policy-making processes in Iran.

Materials and Methods: This multiphasic study consists of a scoping review of existent HCP modalities for the elderly population worldwide, and the disposition of an optimal HCP scheme for the elderly population and its application for the detection of the gaps in Iran. The final stage includes a Delphi-based consultation and consensus process which was reciprocated in three rounds and the key subjects were requested to give their judgment on the eventuated HCP layout designed to serve the ageing Iranian population.

Results: The yielded model (IEHCG-IR) included four dimensions consistent with the four levels of prevention along with social support services. The structure and feasibility of the preliminary framework were approved by $83.6 \%$ of the study participants.

Conclusion: The study findings could have important implications for future policy making in the INHS and the suggested healthcare framework for the elderly Iranian population could be a preliminary model for health system re-engineering.

Keywords: healthcare, elder, aged, model, Iran

\section{Introduction}

Population ageing has been steadily on the rise in Iran during the last 3 decades with considerable socio-economic impacts. The aged population ( $>60$ years old) ratio raised from $5.4 \%$ in 1986 to $8.6 \%$ in 2016 which represents an increase of 4.3 million in the number of elderly Iranian people over a time span of 30 years. ${ }^{1}$ This trend of demographic change is expected to continue and by 2040 there will be extensive consequences, especially in the number of chronic health conditions amongst older people. Therefore, it is expected that the need for social and health care services will increase in order to accommodate the changes in patterns of health and illness and this in turn would add a burden of comorbidities on the country's national health care system. ${ }^{2}$

The majority of aged people will be admitted to health care centers at some time or other, with multiple chronic conditions. In such situations preventing and treating 
acute illnesses will require an integrated approach with several methods of assessing, treating, and caring for the aged patients. The integration has been defined as

a discrete set of techniques and organizational models designed to create connectivity, congruence and collaboration within and between the cure and care sectors at funding, administrative and/or provider levels.

The emphasis is on employing a partnership approach to integrate all services together and to ensure that all target groups, particularly the frail and elderly receive health services. ${ }^{3}$ The required integration must be implemented at different levels of health care provision including the macro level (establishing the general statutory framework by policy maker) meso-level (establishing cooperative relations between organizations) and micro level (in taking initiatives to assure autonomy of health care providers). ${ }^{4}$

In many developed countries, the majority of older people receive disintegrated and fragmented health care services. ${ }^{5}$ This is while; an integrated and comprehensive package of health care services is needed to maintain physical, mental and social wellbeing of older people. ${ }^{6}$ Meager financial and logistic source of health care services, in developing and under developed countries, calls for the effective and efficient use of existing resources to maximize sustainability and responsiveness of the health care systems. ${ }^{7}$

The Delphi technique includes certain features, such as the existence of an expert panel, the ability of response repetition to questionnaires in limitless rounds and receiving comments from previous rounds, statistical analysis of responses and anonymity of participants. The ability of collecting the ideas and opinions of experts is another advantage of this technique that are far away geographically, at a low cost. ${ }^{8}$ Delphi technique has frequently been used in a mixed systematic reviews and gap analysis of health care services. ${ }^{9,10}$

The growing elderly population in Iran and its inevitable impacts on the demand-side of the health care provision equilibrium in coming decades call for an urgent revision of the current policies and health care arrangement in the country's national health care system (INHS). ${ }^{11}$ The main assumption is that reorganizing existing frameworks and resources for provision of a more coherent set of health care services for elderly people could respond to the growing pressure of healthcare needs and comorbidities of the aged Iranian population.
The main aim of this study was to scrutinize the best available scientific evidence on the international integrated elderly health care governance (HCG) models to improve health care practice and policy-making. Based on the retrieved evidence an organizational gap analysis was performed to identify the gap between the status quo health care policies and organizational settlements in Iran and a proposed optimal health care delivery armamentarium applicable for the elderly population.

\section{Materials and Methods}

A combination of three steps including the best available scientific evidence reviews, selecting evidence for input parameters and the model structures, gap analysis and consensus reaching process (CRP) on components of a conceptual model for the provision of elderly healthcare in Iran and qualitative verification of the drafted model by cross-examination of the comments made by the experts to justify their validation as well as their suggestions for improvement ${ }^{12,13}$ were utilized to guide the development of the framework (IEHCG-IR).

\section{Phase I: Scoping Review of Current Health Care Provision Modalities for the Elderly Population}

An extended literature search was performed using relevant MeSH terms (health, social care, care, case management, integrated care, ageing, aging, aged, older, elderly, senior, geriatric) and their Persian equivalents in PUBMED, Cochrane library, Proquest, Ovid Medline and Science Direct to retrieving scientific evidence concerning the health care models, synopses of organizational mandates and policy reports and also research activities geared towards the introduction of conceptual or ideal-typical frameworks (at macro level) to meet the needs of elderly people worldwide that were published before May 2019. Hand searching (Google Scholar and related fields' websites) was also performed to find grey literature and evidence that was not recognized in database searching to find the aged people targeted routine health care delivery arrangements and policies in Iran, webpages of the Iranian Ministry of Health and Medical Education and relevant uploaded electronic reports were also scrutinized (Figure 1).

The identified scientific evidences were assessed by the two authors (MA and AS) for relevancy according to the inclusion criteria, that is, quantitative and qualitative 


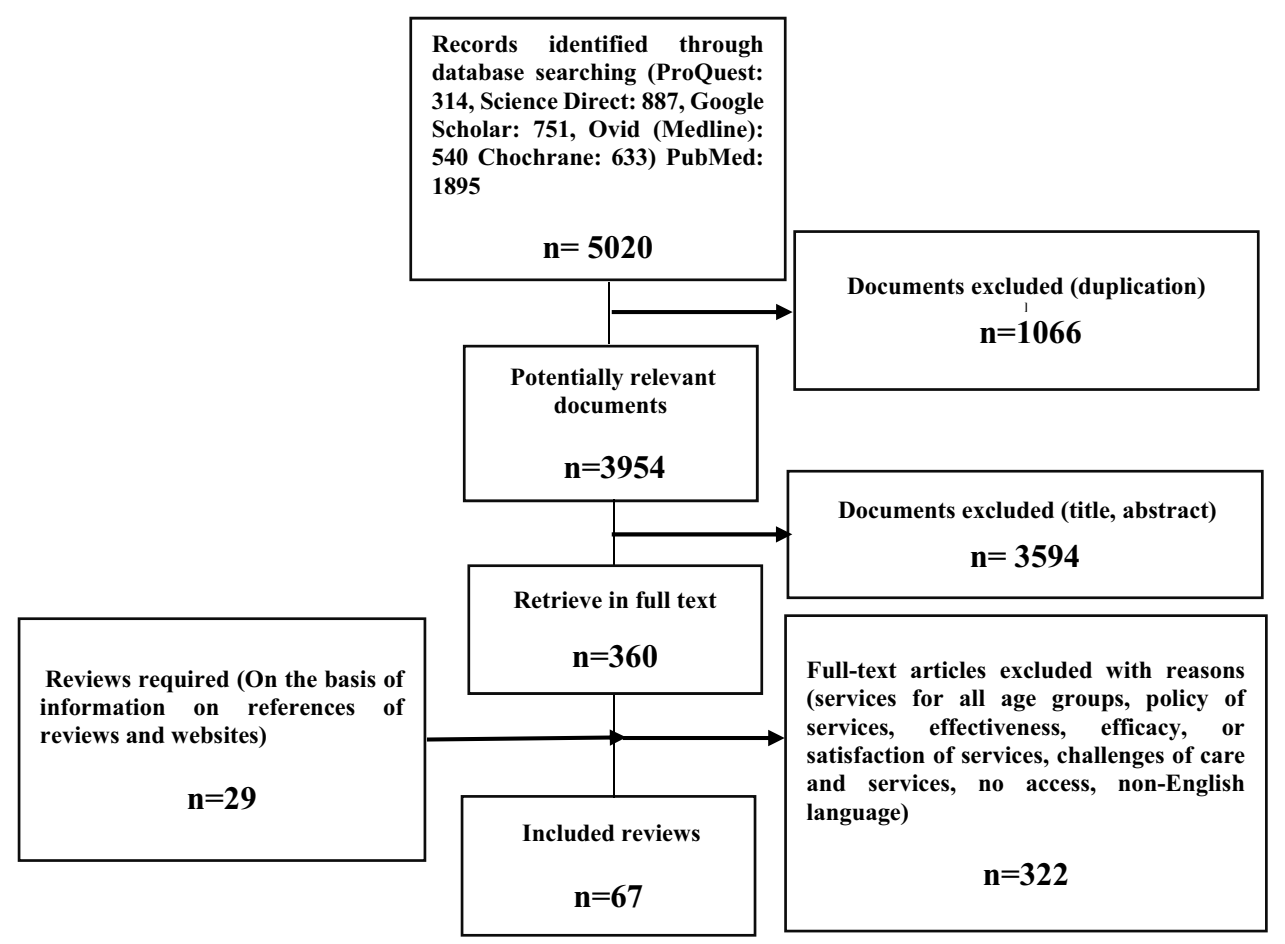

Figure I Flowchart of the publications' selection process: consolidation of research evidence to find gap in elderly health care governance (HCG) in Iran.

reports in English or Persian that discussed components of a theoretical model for elderly health care provision. The publications referring to challenges, effectiveness or efficiency assessment of health care systems or publications that had focused on consumer satisfaction were excluded. The study data synthesis was carried out in descriptive form by summarizing the extracted data about the components of an optimal health care delivery plan for their exploration in a preliminary draft of health care provision model for the elderly Iranian population. The outlined model was conceived based on a gap analysis to identify the main areas of concern and imbalance in HCG to meet the elderly Iranians' health needs. The simple checklist approach was utilized in the gap analysis methodology to list the types of health care/services that are granted for older people in other countries of the world but not provided for the aged Iranian population.

\section{Phase 2: Disposition of an Optimal Health Care Delivery Scheme for the Elderly Population}

The identified dimensions and components of health systems that had been explicitly arranged to cover older population health needs were screened and a conclusive framework was devised as a gold standard presumptive scheme for comparison and gap analysis purposes. The underpinned core structure was employed to compare the existing INHS's health care provision policies and running programs in serving the country's aged population.

\section{Phase 3: Exploration of Key Informants' Perspectives on a Purposed Gold Standard Health System Arrangement to Serve the Elderly Population}

The Delphi technique was utilized to examine a selected group of key subjects' perspectives including INHS's elderly health care chief officers along with gerontology, elderly health and public health specialists regarding the adapted presumptive gold standard health care system scheme with regard to its comprehensiveness and feasibility for possible application in Iran.

The approached subjects were all provided with an outline of the key questions and questioned regarding what they perceived to be suitable components and the arrangement for a conceptual EHCG model for Iran. Due to their work experience and having knowledge about INHS's current hurdles in providing the required healthcare for the country's elderly population, they were assumed to be legitimate candidates for becoming members of the advisory panel in the Delphi rounds. 
The adapted model had four main dimensions to cover preventive, medical, rehabilitative and the daily life support needs of the aged population.

The study participants were asked to give their opinions on the blueprint of the aimed gold standard framework to provide the required healthcare for the elderly population of Iran. The respondents were requested to express their sentiments about the necessity and feasibility of each individual component of the drafted model on a 5point Likert-type scaling option (from strongly disagree to strongly agree). They were also encouraged to comment on and give their recommendations about any item within the pondered schema or add to the assumed items if they came to the conclusion that neglected elements existed. The Delphi-based consultation and consensus reaching process was reciprocated in three rounds and in the final round the study subjects were urged to give their judgment on the eventuated version of the healthcare provision layout.

The study protocol was assessed and approved by the institutional level Medical Ethics Board of Trustees (MEBoT) within the Tabriz University of Medical Sciences (approval number: 5-4-8098-93-09-05).

\section{Results}

The literature search for recognition of admissible scientific evidence yielded 67 studies from mainly developed and economically affluent countries including 34 from the USA, ${ }^{14-47} 2$ reports from Australia, ${ }^{4-50} 10$ documents from Canada, ${ }^{51-60} 1$ from China, ${ }^{61} 3$ from Denmark, ${ }^{5,62,63}$ 5 from England, ${ }^{64-68} 1$ from Finland, ${ }^{69} 2$ from France, ${ }^{70,71} 2$ from Greece, ${ }^{72,73} 3$ from Sweden, ${ }^{4,74,75} 2$ from Japan, ${ }^{76,77}$ and 2 from Italy. ${ }^{78,79}$

Among the identified publications a wide range of suggested components for a comprehensive EHCG were tabulated that can be classified in four prevention levels, that is, primordial, primary, secondary and tertiary. The provision of primary healthcare in 14 documents, certain types of secondary level health services in 17 reports, the provision of a list of definite tertiary level rehabilitation services in 3 publications and delivery of different kinds of social support care in 12 records were assumed to be essential for elder people. A combination of healthcare services in all four levels of prevention were also elucidated in 42 documents. Thorough scrutiny of the retrieved scientific evidence resulted in a comprehensive priori list of healthcare components that had been prompted to best meet old peoples' aggravating health care requirements.
The list included explicit health care/services based on their inherent nature, that is, preventive and medical care/services, rehabilitative and social support services (Table 1).

Intensive review of existing empirical evidences for dimensions and types of elderly healthcare or services in Iran also yielded an elucidated list (Table 2) besides the routine healthcare or social support services that are currently provided to the country's general population. The routine healthcare for the elderly population in Iran across the primordial, primary and secondary prevention levels includes nutrition education, screening and treatment of common diseases that are provided in rural and urban healthcare centers. The proposed healthcare, however, does not cover all the country's aged people especially in the urban areas and provides only minimal treatment in the catchment areas of health centers. A number of elderly healthcare centers have also been established in recent years to provide mainly primary and secondary level health care services to the elderly in the major cities of the country but the workforce's unfamiliarity with old peoples' specific health needs, due to their irrelevant or insufficient educational backgrounds and also the inadequate number of health centers for the elderly to cover all or the majority of the country's elderly population is another burdensome obstacle.

Conventional home health care services for elderly people, ${ }^{25-28,51}$ volunteers who train to gain from their abilities in healthcare provision in order to serve elderly people, ${ }^{41}$ the provision of active healthcare, ${ }^{41}$ the provision of physical activity facilities, ${ }^{5,54,68}$ meal services, 5,62,63 immunization against common diseases in the elderly ${ }^{76,77}$ and free or subsidized healthcare services ${ }^{20,26,29,31,68}$ are among the list of facilities that are scheduled in mostly developed countries for the ageing population but they are not currently available for the elderly Iranian population.

Comparison of the already scheduled health and health-related services for the aged Iranian population (Table 2) and constituents of an intended comprehensive package of healthcare retrieved from the consolidation of available international evidence (Table 1) yielded a tenable preliminary model of healthcare for elderly Iranians. The model was sent to a group of key subjects in a three-round Delphi procedure to obtain their comments about the applicability of the model in Iran and about possible revision that could be done for the model integrity. Among the 22 approached subjects only 19 
Table I Inherent Nature and Explicit List of the Elderly Health Care/Services Retrieved from Consolidation of the Global Scientific Evidence

\begin{tabular}{|c|c|c|}
\hline $\begin{array}{l}\text { Inherent } \\
\text { Nature of } \\
\text { Care/ } \\
\text { Services }\end{array}$ & $\begin{array}{l}\text { Providing } \\
\text { Organization/ } \\
\text { Institution }\end{array}$ & Types of Care/Services \\
\hline $\begin{array}{l}\text { Preventive \& } \\
\text { medical care/ } \\
\text { services }\end{array}$ & $\begin{array}{l}\text { INHS/NGOs/ } \\
\text { Charities/Private } \\
\text { profitable sectors }\end{array}$ & $\begin{array}{l}\text { - Healthy lifestyle education } \\
\text { - Screening for prevalent elderly } \\
\text { diseases } \\
\text { - Home health care facilities } \\
\text { - Day hospital services } \\
\text { - Vision and dental care } \\
\text { - Mental health services }\end{array}$ \\
\hline Rehabilitative & $\begin{array}{l}\text { IWO/NGOs/ } \\
\text { Charities }\end{array}$ & $\begin{array}{l}\text { - Rehabilitation services (phy- } \\
\text { siotherapy, occupational/speech } \\
\text { therapy) } \\
\text { - Day care and residential home } \\
\text { facilities } \\
\text { - Provision of assistive devices } \\
\text { (hearing aids, glasses, wheel- } \\
\text { chairs, walkers) }\end{array}$ \\
\hline $\begin{array}{l}\text { Social } \\
\text { support }\end{array}$ & $\begin{array}{l}\text { Governmental or } \\
\text { public pension } \\
\text { funds/IWO/ } \\
\text { NGOs/Charities/ } \\
\text { IKRF }\end{array}$ & $\begin{array}{l}\text { - Financial aids/loans to build, buy } \\
\text { or lease a house or a required } \\
\text { - } \text { medical equipment. } \\
\text { - Sport and exercise facilities } \\
\text { - Financidizing intercity transportation supporting elderly care } \\
\text { centers } \\
\text { - Financially supporting recreational } \\
\text { - } \text { activities } \\
\text { - Payments of pension/living costs } \\
\text { - General/supplementary health } \\
\text { - Volunteer agencies' programs }\end{array}$ \\
\hline
\end{tabular}

Abbreviations: INHS, Iranian National Health System; NGOs, Non-Governmental Organizations; IWO, Iranian Welfare Organization; IKRF, Imam Khomeini Relief Foundation.

agreed to participate in the study (response rate $82.6 \%$ ). The model components were kept if the majority of the respondents $(>50 \%)$ were in favor of necessity and feasibility of each individual component. Based on the participants' comments minor revisions or amendments were also made in the model constructs to best fit with the INHS's capacities and weaknesses, eg, in the arranging of a multidisciplinary healthcare team in health centers, the setting-up of inpatient and outpatient care centers to provide $24 \mathrm{~h}$ health and social care and shortages of required expertise in middle and upper policy-making levels in fulfilling health care needs of the country's growing elder population. The eventuated
Table 2 Inherent Nature and List of the Provided Explicit Elderly Health Care/Services in Iran

\begin{tabular}{|c|c|}
\hline $\begin{array}{l}\text { Inherent Nature of } \\
\text { Care/Services }\end{array}$ & Types of Care/Services \\
\hline $\begin{array}{l}\text { Preventive \& medical } \\
\text { care/services }\end{array}$ & $\begin{array}{l}\text { - Peer to peer education } \\
\text { - Recruitment of volunteer health workers } \\
\text { - Immunization against common elderly diseases } \\
\text { - } 24 \text { hour hotline counseling } \\
\text { - Home health care facilities } \\
\text { - Daycare facilities } \\
\text { - Night care facilities } \\
\text { - Day hospital services } \\
\text { - Vision and dental care } \\
\text { - Mental health services } \\
\text { - Assistance to obtain durable/specialized } \\
\text { - Tele \& mobile health/medical services } \\
\text { - District nursing services } \\
\text { - Specialist dementia service } \\
\text { - Limited medical services such as podiatry care }\end{array}$ \\
\hline Rehabilitative & $\begin{array}{l}\text { - Institution-based rehabilitation } \\
\text { - Hospice care } \\
\text { - Ergo therapy programs } \\
\text { - Mobile rehabilitation }\end{array}$ \\
\hline Social support & $\begin{array}{l}\text { - Chore services (assistance with housekeep- } \\
\text { ing, bathing, grooming, etc.) } \\
\text { - Pension payment/fee waivers for healthcare/ } \\
\text { social services } \\
\text { - Assisted living facilities } \\
\text { - Transporting facilities to attend medical/ } \\
\text { - health care centers } \\
\text { - Reimbursement scheme for elderly health/ } \\
\text { - geriatric services } \\
\text { - General/supplementary health insurance } \\
\text { - Durable medical equipment and pharmacy } \\
\text { - Conefits } \\
\text { - Recreational services } \\
\text { - Legal and financial counseling } \\
\text { - Custodial nursing home care } \\
\text { - Respite care } \\
\text { - Volunteer agencies' programs } \\
\text { - Access to reading/audiovisual materials/ } \\
\text { informal socialization events } \\
\text { - Access to exercise/sport facilities } \\
\text { - Provision of space in public places for resting } \\
\text { - Fr taking a nap } \\
\text { - Senior errand services } \\
\text { - Wireless alarm system } \\
\text { - Specialized services to isolated/lonely elderlies }\end{array}$ \\
\hline
\end{tabular}

version (Figure 2) was agreed in the final stage by $83.6 \%$ of the participants. 


\section{Discussion}

This study aimed at highlighting the gap which exists in the provision of healthcare to the elderly Iranian population and suggests a proposed comprehensive model of care to be adapted in Iran. Applying a multi-method design, the researchers tried to base their suggested model of care on sound scientific evidence and assess its feasibility according to the national key subjects' prospects.

The yielded framework in fulfilling the healthcare needs of the elderly Iranian population (IEHCG-IR) included four dimensions consistent with the four levels of prevention; that is, primordial and primary care, secondary and tertiary care dimensions along with social support services as indicated in Figure 2.

The current identified shortcomings in the INHS to respond to the elderly population health needs include lack of dedicated programs for regular health checkups, immunization against common infectious diseases prevalent in old age, screening for major old age morbidities, eg, cardio vascular disease, cancers, diabetes and neuropsychological impairments, rehabilitative daycare and hospital-based services, home visits, clinical and homebased psychological assessments, transportation facilities, payment of pension and caregiver support services reflect the pathway of change required.

Many of the mentioned services are already provided in developed countries Greece, ${ }^{72}$ USA, $^{21,24,36,45}$ Sweden, ${ }^{80}$ Australia, ${ }^{49}$ and Denmark, ${ }^{5}$ with greater emphasis on preventive home visits, further cooperation across care providing organizations and mobilizing national-level resources for an integrated community-based care provision.

Iran is a transitional country with a rapidly growing population of old people. The current arrangements for elderly-specific care provision in the country suffer from patchy mid and upper level organizational policy formulation. Most of the provided care for elderly people in Iran is institution based (health centers, clinics and hospitals) and little investment goes towards integrated community-based initiatives. Therefore, due to the gaps in the provision of all required health and social care for the elderly Iranian population especially in relation to the services that are categorized in primordial and primary prevention levels,

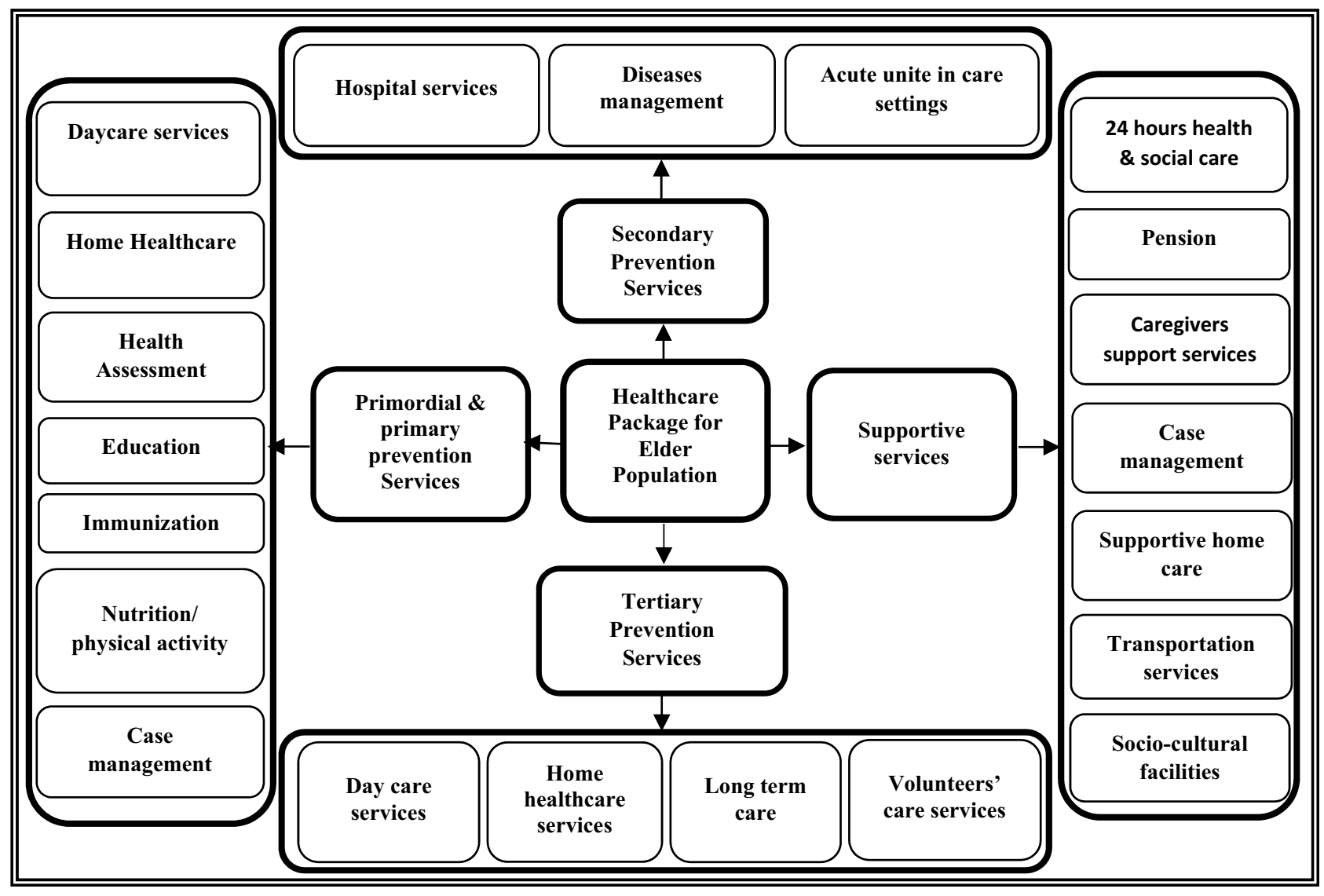

Figure 2 Schematic diagram of a comprehensive model of healthcare provision for older people: based on the consolidation of empirical scientific evidence and Iranian key informants' perspectives. 
considerable pressure and demanding workloads are exerted on healthcare staff in healthcare centers or hospitals by those elderly patients that have encountered complicated but preventable health problems. ${ }^{81}$

Based on the current empirical data about half of the hospital beds are occupied by elderlies worldwide especially by those in the range of over 85 years old. ${ }^{82}$ Such a pattern of hospital bed occupation could be devastating for resource-limited countries and cause a lack of sufficient beds available to serve other age groups hospital-based healthcare needs. Thus, planning and the provision of a comprehensive package of care for elderly people could not only answer old peoples' needs but at the same time could lead to cost-effectiveness and a better availability of constrained healthcare facilities to whole populations. This is even pivotal in the resource-limited countries of the world. Chronic disease-induced need for long-term hospitalization, uncontrolled psycho-cognitive impairments and bedsores in old people are examples of complications that might put extra pressure on health systems within the general constraint of limited financial resources. This is while, empirical international evidence exists to set up an integrated community-based healthcare services for elderly people that could lead to better allocation of resources and an overall better healthcare outcome.

The willingness of older people to live independently ${ }^{83,84}$ and its positive psychosocial impacts further herald the importance of a comprehensive community-based healthcare framework for this sub group of populations and the required revisions that must be planned for maximum repercussion of the healthcare system cost-effectiveness.

Access to the required healthcare by all and especially by vulnerable subgroups of the population is a universal theme which is highlighted in many national and international plans of actions. The study findings revealed that the current healthcare structure and policies in Iran are failing to adequately fulfill the old population's health needs. The INHS suffers from inadequacy in providing equitable healthcare services to a sizable subgroup of the country's population; therefore, access to the required and sometimes live-saving care for the ageing Iranian population could be overwhelming. This gap might even be wider for those old people who live in deprived and marginalized areas of the country. The difference could represent inherent social inequality in distinct geographical regions of the country which may inadvertently marginalize old people due to intrinsic inaccurate health policies. ${ }^{85}$ The embedded malformed policies in healthcare systems could lead to unequal distribution of health and therefore deepening of healthcare inequalities. The synergistic interplay between financial constraints and the absence of sound policy-making procedures leads to a trajectory shift in the country's health system priorities.

This study finding must be interpreted with caution due to certain limitations. First, cross-sectional design of this study only represents current available data in relation to a comprehensive model of healthcare provision for elderly adults. The wide range of expertise the study respondents had in the Delphi stage of the study might cast uncertainty on the study findings since; there is the probability of different interpretations of the proposed model of care provision for elderly Iranian people and its feasibility in practice. The applied paper-based selfreporting of the key subjects' prospects could potentially be another source of bias in this study due to our inability to attain the subjects' details about the idea about the model and its interpretation on the suggested dimensions. Due to logistics and time restraints, an overall prospect of the Iranian key subjects (policy makers, scholars, health care managers ...) was assessed in this study about feasibility of the devised theoretical model for application in care provision to the country's elder population. A multidimensional future study is required to cluster all features of an ideal health care provision model (that includes financing, delivery model, human resources) relative to infrastructure and socio-economic circumstances of the country.

The possibility of identification bias due to missing important original studies in the scoping review of the literature and interpretation bias due to tendency of the researchers to inappropriately analyze the study data for gap analysis based on a priory default mindset should not be ruled out completely in this study either.

\section{Conclusion}

The study findings could have important implications for future policy making in the INHS and the suggested healthcare framework for the elderly Iranian population could be a preliminary model for health system re-engineering. Previous international evidence addressed the importance of an integrated and comprehensive healthcare system in responding to old peoples' healthcare needs. The available evidence, however, was not translated into knowledge to pursue an evidence-informed decision making process in the INHS to obtain the healthcare rights of the elderly Iranian population. A higher level of organizational 
commitment, evidence-informed policy interventions and intersectional collaboration is needed in order to have a more equitable healthcare system in Iran. Further research is recommended to investigate organizational and infrastructure barriers in the establishment of an integrated healthcare governance to respond to elderly Iranian populations and those of countries similar to Iran.

\section{Funding}

This study was partially supported by a grant from the Tabriz University of Medical Sciences (grant number: 5-53-5561-93-09-24) and was conducted, in part, to fulfill the first author's (MA) requirements for a master's degree.

\section{Disclosure}

The authors report no conflicts of interest in this work.

\section{References}

1. Roudi F, Azadi P, Mesgaran M Iran's population dynamics and demographic window of opportunity. Working Paper 4, Stanford Iran 2040 Project. Stanford University; October 2017.

2. Mehri N, Messkoub M, Kunkel S. Trends, determinants and the implications of population aging in Iran. Ageing Int. 2020. doi:10.1007/s12126-020-09364-z

3. MacAdam M. Frameworks of Integrated Care for the Elderly: A Systematic Review. Canadian Policy Research Networks; 2008.

4. Calciolari S, Ilinca S. Organizing integrated care for frail elderly patients in Switzerland, Italy, United States and Canada. In: Bergmann A, editor. Yearbook of Swiss Administrative Sciences. Zurich: SGVW; 2011.

5. Colmorten E, Clausen T, Bengtsson S. Providing integrated health and social care for older persons in Denmark. In: Leichsenring K, Alaszewski AM, editors.Providing Integrated Health and Social Care for Older Persons - A European Review of Issues at Stake. Vienna: European Centre and Aldershot: Ashgate Publishing; 2004:139-180.

6. Dadkhah A. Elderly care system in America and Japan, providing indicators for strategic planning in aged care services. Iran J Ageing. 2005;2(3):168.

7. Hirth V, Baskins J, Dever-Bumba M. Program of all-inclusive care (PACE): past, present, and future. J Am Med Dir Assoc. 2009;10 (3):155-160. doi:10.1016/j.jamda.2008.12.002

8. Zeigler VL, Decker-Walters B. Determining psychosocial research priorities for adolescents with implantable cardioverter defibrillators using Delphi methodology. J Cardiovasc Nurs. 2010;25(5):398-404. doi:10.1097/JCN.0b013e3181d817b0

9. Girlanda F, Fiedler I, Becker T, Barbui C, Koesters M. The evidencepractice gap in specialist mental healthcare: systematic review and meta-analysis of guideline implementation studies. Br J Psychiatry. 2016.

10. Christoglou K, Vassiliadis C, Sigalas I, Mylonakis J. A comparative study of healthcare services gap analysis approach in the provision of efficient hospital treatment. J Int Diversity. 2012;2012(2).

11. Mirzaie M, Darabi S. Population aging in Iran and rising health care costs. Iran J Ageing. 2017;12(2):156-169.

12. Rautenberg T, Hulme C, Edlin R. Methods to construct a step-by-step beginner's guide to decision analytic cost-effectiveness modeling. Clinicoecon Outcomes Res. 2016;8:573-581. doi:10.2147/CEOR. S113569
13. Mathisen E, Krogstie J Modeling of processes and decisions in healthcare - state of the art and research directions. 5th Working Conference on the Practice of Enterprise Modeling (PoEM); November 2012:101-116; Rostock, Germany. doi: 10.1007/978-3642-34549-4_8

14. Keister D, Shvetzoff S. Allowing the elderly to age in place. In Portland, OR, a catholic-sponsored PACE site provides communitybased health care services. Health Prog. 2004;85(6):50-53.

15. Schraeder C, Britt T. The Carle clinic. Nurs Manage. 1997;28(3):3234. doi:10.1097/00006247-199703000-00010

16. Borgenicht K, Carty E, Feigenbaum LZ. Community resources for frail older patients. West J Med. 1997;167(4):291-294.

17. Kane RL, Homyak P, Bershadsky B, Lum YS. Consumer responses to the Wisconsin Partnership Program for Elderly Persons: a variation on the PACE model. J Gerontol a Biol Sci Med Sci. 2002;57(4): M250-M258. doi:10.1093/gerona/57.4.M250

18. Counsell SR, Callahan CM, Tu W, Stump TE, Arling GW. Cost analysis of the geriatric resources for assessment and care of elders care management intervention. J Am Geriatr Soc. 2009;57(8):14201426. doi:10.1111/j.1532-5415.2009.02383.x

19. Bendixen RM, Levy CE, Olive ES, Kobb RF, Mann WC. Cost effectiveness of a telerehabilitation program to support chronically ill and disabled elders in their homes. SO-Telemed $J$ E-Health. 2009;15(1):31-38. doi:10.1089/tmj.2008.0046

20. Ryan J, Super N. Dually eligible for medicare and medicaid: two for one or double jeopardy? NHPF Issue Brief. 2003;30(794):1-24.

21. Evashwick CJ, Cohn J. Enhancing managed care's role in long-term care: building on the aging network. Manag Care Q. 1999;7(1):39-45.

22. Shelton P, Schraeder C, Britt T, Kirby R. A generalist physicianbased model for a rural geriatric collaborative practice. $J$ Case Manag. 1993;3(3):98-104.

23. Wideman M. Geriatric care management: role, need, and benefits. Home Healthc Nurse. 2012;30(9):553-559. doi:10.1097/NHH.10 90b1013e31822a30637

24. Counsell SR, Callahan CM, Buttar AB, Clark DO, Frank KI. Geriatric resources for assessment and care of elders (GRACE): a new model of primary care for low-income seniors. $J$ Am Geriatr Soc. 2006;54(7):1136-1141. doi:10.1111/j.1532-5415.2006.00791.x

25. Golden AG, Roos BA, Silverman MA, Beers MH. Home and communitybased Medicaid options for dependent older Floridians. J Am Geriatr Soc. 2010;58(2):371-376. doi:10.1111/j.1532-5415.2009.02668.x

26. Caro FG, Porell FW, Sullivan DM, Safran-Norton CE, Miltiades H. Home health and home care in Massachusetts after the Balanced Budget Act of 1997: implications of cost containment pressures for service authorizations. Home Healthc Serv Q. 2002;21(1):47-66. doi:10.1300/J027v21n01_03

27. Edwards DF, Baum CM, Meisel M, et al. Home-based multidisciplinary diagnosis and treatment of inner-city elders with dementia. Gerontologist. 1999;39(4):483-488. doi:10.1093/geront/39.4.483

28. Schoenfelder DP, Maas ML, Specht JK. HomeSafe: supportive assistance for elderly individuals through a nurse-managed plan. J Gerontol Nurs. 2005;31(4):5-11. doi:10.3928/0098-9134-20050401-04

29. Dobell LG, Newcomer RJ. Integrated care: incentives, approaches, and future considerations. Soc Work Public Health. 2008;23(4):2547. doi:10.1080/19371910802162116

30. Freed DM, Elder WW, Lauderdale S, Carter S. An integrated program for dementia evaluation and care management. Gerontologist. 1999;39(3):356-361. doi:10.1093/geront/39.3.356

31. Yaggy SD, Michener JL, Yaggy D, et al. Just for US: an academic medical center-community partnership to maintain the health of a frail low-income senior population. Gerontologist. 2006;46(2):271276. doi:10.1093/geront/46.2.271

32. Doyle A, Masland J. Managed care for the elderly in the United States: outcomes to-date and potential for future growth. Health Policy (New York). 1997;41:S145-62. doi:10.1016/S0168-8510(97) 00044-4 
33. Harrington C, Lynch M, Newcomer RJ. Medical services in social health maintenance organizations. Gerontologist. 1993;33(6):790 800. doi:10.1093/geront/33.6.790

34. Wimberley ET, Blazyk S. Monitoring patient outcome following discharge: a computerized geriatric case-management system. Health Soc Work. 1989;14(4):269-276. doi:10.1093/hsw/14.4.269

35. Gerber L. Moving into private geriatric nursing care management. Am J Nurs. 2010;110(1 Suppl):22-24. doi:10.1097/01.NAJ.000 $0366157.41070 .7 \mathrm{a}$

36. Karlin BE, Karel MJ. National integration of mental health providers in VA home-based primary care: an innovative model for mental health care delivery with older adults. Gerontologist. 2014;54 (5):868-879. doi:10.1093/geront/gnt142

37. Bartsch DA, Rodgers VK, Strong D. Outcomes of senior reach gatekeeper referrals: comparison of the Spokane gatekeeper program, Colorado Senior Reach, and Mid-Kansas Senior Outreach. Care Manag J. 2013;14(1):11-20. doi:10.1891/1521-0987.14.1.11

38. Rassen AG. Seniors-at-home: a case management program for frail elders. JCOM-WAYNE PA. 2003;10(11):603-607.

39. Bendixen R, Horn K, Levy C. Using telerehabilitation to support chronically ill elders in their homes. Top Geriatr Rehabil. 2006;23:47-51. doi:10.1097/00013614-200701000-00007

40. Kodner DL. Whole-system approaches to health and social care partnerships for the frail elderly: an exploration of North American models and lessons. Health Soc Care Community. 2006;14(5):384390. doi:10.1111/j.1365-2524.2006.00655.x

41. Barrett DL, Secic M, Borowske D. The Gatekeeper Program: proactive identification and case management of at-risk older adults prevents nursing home placement, saving healthcare dollars program evaluation. SO - Home HealthcNurse. 2010;28(3):191-197. doi:10.1097/01.NHH.0000369772.41656.4e

42. Bielaszka-DuVernay C. Innovation profile: the 'GRACE' model: inhome assessments lead to better care for dual eligibles. Health Aff. 2011;30:431-434. doi:10.1377/hlthaff.2011.0043

43. Baseman S, Truxell R. Developing an IDS-based disease-management program for the frail elderly. Healthc Financ Manage. 2000;54 (2):33-36.

44. Baldwin KM. Elder case management by registered nurses. Prof Case Manag. 2013;18(1):15-22. doi:10.1097/NCM.1090b1013e31826b318 12 be

45. Wieck KL. Health promotion for inner-city minority elders. $J$ Community Health Nurs. 2000;17(3):131-139. doi:10.1207/S15327 655JCHN1703_01

46. Parker M, Secord LJ. Private geriatric case management: providers, services, and fees. SO - Nurs Econ. 1988;6(4):165-172.

47. Kohn R, Goldsmith E, Sedgwick TW. Treatment of homebound mentally ill elderly patients: the multidisciplinary psychiatric mobile team. Am J Geriatr Psychiatry. 2002;10(4):469-475. doi:10.1097/ 00019442-200207000-00013

48. Leichsenring K. Developing integrated health and social care services for older persons in Europe. Int J Integr Care. 2004;4.

49. Henderson EJ, Caplan GA. Home sweet home? Community care for older people in Australia. J Am Med Dir Assoc. 2008;9(2):88-94. doi:10.1016/j.jamda.2007.11.010

50. Roberts RM, Dalton KL, Evans JV, Wilson CL. A service model of short-term case management for elderly people at risk of hospital admission. Aust Health Rev. 2007;31(2):173-183. doi:10.1071/ ah070173

51. Kelly J, Orr A. Accountability, responsiveness and quality for clients model of home support: a model for improved home support services to promote aging at home. Healthc Pap. 2009;10(1):65-71; discussion 79-83. doi:10.12927/hcpap.2009.21225

52. Truman CD Articulating program impact theory for the Comprehensive Home Option of Integrated Care for the Elderly (CHOICE); 2000
53. Bergman $\mathrm{H}$, Beland $\mathrm{F}$, Lebel $\mathrm{P}$, et al. Care for Canada's frail elderly population: fragmentation or integration? CMAJ. 1997;157(8):11161121.

54. Biette Burns MG. Coordinated community health services for the elderly. Can J Public Health. 1984;75(6):458-462.

55. Hebert R, Durand PJ, Dubuc N, Tourigny A. Frail elderly patients. New model for integrated service delivery. Can Fam Physician. 2003;49:992-997.

56. Béland F, Bergman H, Lebel P, et al. Integrated services for frail elders (SIPA): a trial of a model for Canada. La revue canadienne $d u$ vieillissement [Can J Aging]. 2006;25:5-42. doi:10.1353/cja.2006.0018

57. de Stampa MD, Vedel I, Bergman H, et al. Opening the black box of clinical collaboration in integrated care models for frail, elderly patients. Gerontologist. 2013;53(2):313-325. doi:10.1093/geront/gns081

58. Carrier S. Service coordination for frail elderly individuals: an analysis of case management practices in Quebec. J Gerontol Soc Work. 2012;55(5):392-408. doi:10.1080/01634372.01632011.01647388

59. Stewart MJ, Georgiou A, Westbrook JI. Successfully integrating aged care services: a review of the evidence and tools emerging from a long-term care program. Int $J$ Integr Care. 2013;13:e003. doi:10.5334/ijic. 963

60. Freeman M, Zack E. Triaging seniors in health crisis in the emergency department: a three-year summary. Perspectives. 1996;20 (3):8-11

61. Wu B, Carter MW, Goins RT, Cheng C. Emerging services for community-based long-term care in urban China: a systematic analysis of Shanghai's community-based agencies. SO - J Aging Soc Policy. 2005;17(4):37-60. doi:10.1300/J031v17n04 03

62. Hansen EB. Integrated care for vulnerable older people in Denmark. Healthc Pap. 2009;10(1):29-33;79-83. doi:10.12927/hcpap.2009.21220

63. Ekmann A, Vass M, Avlund K. Preventive home visits to older homedwelling people in Denmark: are invitational procedures of importance? Health Soc Care Community. 2010;18:563-571.

64. Challis D, Stewart K, Donnelly M, Weiner K, Hughes J. Care management for older people: does integration make a difference? J Interprof Care. 2006;20(4):335-348. doi:10.1080/13561820600727130

65. Hughes J, Reilly S, Berzins K, Abell J, Stewart K, Challis D. Emergent approaches to care coordination in England: exploring the evidence from two national organizations. Care Manag J. 2011;12 (4):194-201. doi:10.1891/1521-0987.12.4.194

66. Challis D, Darton R, Johnson L, Stone M, Traske K. An evaluation of an alternative to long-stay hospital care for frail elderly patients: I. The model of care. Age Ageing. 1991;20(4):236-244. doi:10.1093/ ageing/20.4.236

67. Drennan V, Goodman C. Nurse-led case management for older people with long-term conditions. Br J Community Nurs. 2004;9 (12):527-533. doi:10.12968/bjen.2004.9.12.17241

68. Alaszewski A, Baldock J, Billings J, Coxon K, Twigg J Providing integrated health and social care for older persons in the United Kingdom; 2003

69. Salonen P, Haverinen R. Providing Integrated Health and Social Care for Older Persons in Finland. Providing Integrated Health and Social Care for Older Persons. Aldershot: Ashgate; 2004:181228.

70. Vedel I, De Stampa M, Bergman H, et al. A novel model of integrated care for the elderly: COPA, Coordination of Professional Care for the Elderly. Aging Clin Exp Res. 2009;21(6):414-423. doi:10.1007/BF03327446

71. Somme D, de Stampa M. Ten years of integrated care for the older in France. Int J Integr Care. 2011;11(Spec10th Anniversary Ed):e141. doi:10.5334/ijic. 668

72. Daniilidou NV, Economou C, Zavras D, Kyriopoulos J, Georgoussi E. Health and social care in aging population: an integrated care institution for the elderly in Greece. Int J Integr Care. 2003;3:e04. doi: $10.5334 /$ ijic. 92 
73. Sissouras A, Ketsetzopoulou M, Bouzas N, Fagadaki E, Papaliou O, Fakoura A. Providing Integrated Health and Social Care for Older Persons in Greece. Providing Integrated Health and Social Care for Older Persons. Aldershot: Ashgate; 2004:329-370.

74. Andersson G, Karlberg I. Integrated care for the elderly: the background and effects of the reform of Swedish care of the elderly. Int $J$ Integr Care. 2000;1:e01. doi:10.5334/ijic.7

75. Wolmesjo M, Gollungberg A. Management in care of older persons and persons with disabilities in Sweden. Aotearoa N Z Soc Work. 2011;23(1/2):40. doi:10.11157/anzswj-vol23iss1-2id168

76. Watanabe R, Lai OK. Aged care service delivery in Japan: preparing for the long-term care insurance scheme. J Aging Soc Policy. 2001;13 (2-3):21-34. doi:10.1300/J031v13n02_03

77. Tsutsui T. Implementation process and challenges for the communitybased integrated care system in Japan. Int J Integr Care. 2014;14: e002. doi:10.5334/ijic. 988

78. Landi F, Lattanzio F, Gambassi G, et al. A model for integrated home care of frail older patients: the Silver Network Project. Aging Clin Exp Res. 1999;11(4):262-272. doi:10.1007/BF03339667

79. Nesti G, Campostrini S, Garbin S, et al. Providing integrated health and social care for older persons in Italy. National report. National report; 2003.
80. Sam Aram E, Amin-Aghaei M. Social policies for the elderly in Japan and Sweden as a model for the elderly in Iran. Iran $J$ Ageing. 2007;1(2):88-100.

81. Khoshbin S, Madani Z, Alizadeh M, Pourmorowat S. Integrated and comprehensive care training guidelines. Iran Ministry Health Med Educ. 2009;28(3). [In Persian].

82. Kozak LJ, Hall MJ, Owings M. National Hospital Discharge Survey: 2000 annual summary with detailed diagnosis and procedure data. Vital Health Stat 13. 2002;153:1-194.

83. Sutherland S. Free personal and nursing care in Scotland. Eur View. 2008;7(2):297-302. doi:10.1007/s12290-008-0046-6

84. Pleace N. The Costs and Benefits of Preventative Support Services for Older People. York: The Centre for Housing Policy; 2011.

85. Hui A, Latif A, Hinsliff-Smith K, Chen T. Exploring the impacts of organisational structure, policy and practice on the health inequalities of marginalised communities: illustrative cases from the UK healthcare system. Health Policy (New York). 2020;124(3):298-302. doi:10.1016/j.healthpol.2020.01.003
Risk Management and Healthcare Policy

\section{Publish your work in this journal}

Risk Management and Healthcare Policy is an international, peerreviewed, open access journal focusing on all aspects of public health, policy, and preventative measures to promote good health and improve morbidity and mortality in the population. The journal welcomes submitted papers covering original research, basic science, clinical \& epidemiological studies, reviews and evaluations,

\section{Dovepress}

guidelines, expert opinion and commentary, case reports and extended reports. The manuscript management system is completely online and includes a very quick and fair peer-review system, which is all easy to use. Visit http://www.dovepress.com/testimonials.php to read real quotes from published authors. 